\title{
Voltage-dependent intrinsic bursting in olfactory bulb Golgi cells
}

\author{
R. Todd Pressler, ${ }^{1}$ Peter A. Rozman, ${ }^{1,2}$ and Ben W. Strowbridge ${ }^{1,3}$ \\ ${ }^{1}$ Department of Neurosciences, Case Western Reserve School of Medicine, Cleveland, Ohio 44106, USA
}

\begin{abstract}
In the mammalian olfactory bulb (OB), local synaptic circuits modulate the evolving pattern of activity in mitral and tufted cells following olfactory sensory stimulation. GABAergic granule cells, the most numerous interneuron subtype in this brain region, have been extensively studied. However, classic studies using Golgi staining methods identified many other, nongranule cell types in the $\mathrm{OB}$ whose function remains mysterious. Within just the granule cell layer (GCL), Ramón y Cajal described multiple morphologically distinct subtypes of nongranule interneurons including large spiny Blanes cells which exhibit intrinsic persistent activity. Here, we define the intrinsic electrophysiology of a different nongranule interneuronal cell type in the GCL described by Ramón y Cajal, sparsely spiny Golgi cells in the rat $\mathrm{OB}$. Golgi cells exhibit two distinct firing modes depending on the membrane potential: tonic firing and bursting. Golgi cells also generate rebound bursts following the offset of hyperpolarizing steps. We find that both low-threshold burst responses to depolarizing inputs and rebound bursts are blocked by nickel, an antagonist of T-type voltage-gated $\mathrm{Ca}^{2+}$ current. The state-dependent firing behavior we report in OB Golgi cells suggests that the function of these interneurons may dynamically shift from providing rhythmic potent inhibition of postsynaptic target neurons at sniffing frequencies to tonic, subtractive inhibition based on centrifugal modulatory input.
\end{abstract}

Odorant information is first transduced into neural code by olfactory sensory neurons (OSNs) in the nasal epithelium, and then it is routed to the olfactory bulb (OB), a second-order olfactory processing region (Mori et al. 1999; Shepherd 2004). Here, OSN axons make excitatory inputs onto mitral and tufted cell primary dendrites, and activity from these principal cells is relayed to olfactory cortex and other downstream brain regions (Mori et al. 1999; Shepherd 2004). In the OB, the local inhibitory circuits sculpt the activity of output neurons, and transform a slow activation in OSNs into a rapidly evolving temporal pattern of activity in OB principal cells (Kay and Laurent 1999). The interplay between principal cell intrinsic spiking properties (Balu et al. 2004; Balu and Strowbridge 2007) and inhibition from local circuits governs OB output (Somogyi et al. 1998; Shepherd 2004; Stepanyants et al. 2004).

While classic studies have identified many morphologically defined subtypes of inhibitory interneurons in the OB, functional data are available for relatively few cell types—primarily granule cells (GCs) and interneurons in the glomerular layer (Aungst et al. 2003; Liu et al. 2013). Granule cells, small axon-less interneurons, make up the largest population of interneurons in the $\mathrm{OB}$, and are also the most studied interneuron population. Through reciprocal dendrodendritic synapses, GCs provide the primary source of recurrent and feedforward inhibition onto both mitral and tufted cells outside the glomerular layer (Ezeh et al. 1993; Isaacson and Strowbridge 1998; Shepherd 2004). Granule cellmediated inhibition appears to help modulate principal cell firing output to facilitate decorrelation of overlapping patterns of sensory input during olfactory discrimination tasks (Giridhar et al. 2011; Fukunaga et al. 2012).

\footnotetext{
2Present address: Department of Neurology, Massachusetts General Hospital, Boston, Massachusetts 02114, USA

${ }^{3}$ Corresponding author

E-mail bens@case.edu

Article is online at http://www.learnmem.org/cgi/doi/10.1101/Im.031856.113.
}

The granule cell layer (GCL) contains an especially rich collection of relatively unexplored interneurons. Using Golgi staining methods, Ramón y Cajal (1911) and subsequent researchers have described seven primary subtypes of non-GC cell types in this layer, including Blanes cells, Golgi cells, vertical cells of Cajal, horizontal cells, bi-tufted neurons, deep stellate cells, and deep short axon cells (Schneider and Macrides 1978; LopezMascaraque et al. 1986; Kosaka and Kosaka 2010). Aside from GCs and Blanes cells (Pressler and Strowbridge 2006), there have only been scattered electrophysiological investigations of any of these interneuron subtypes. Defining the electrophysiological properties for these cells is a critical first step to determining the local circuit connections these cells form and how they participate in sensory processing. In many brain regions, morphologically distinct subtypes of interneurons play very different functional roles, including providing inhibition onto specific cellular compartments (e.g., dendritically or somatically targeting interneurons found in many cortical regions and axo-axonic chandelier cells that selectively synapse on axon initial segments; Kawaguchi and Kubota 1997). Whether the OB contains analogous interneuron cell types remains to be determined.

In this report, we describe the intrinsic electrophysiology of Golgi cells, a sparsely spiny interneuron cell type in the GCL originally described by Ramón y Cajal (1911). Unlike GCs, which generate prominent hyperpolarizing potentials following suprathreshold depolarizing steps (Pressler et al. 2007), and Blanes cells, which generate large afterdepolarizations (Pressler and Strowbridge 2006), Golgi cells fail to generate an afterpotential following tonic spiking. Golgi cells generate prominent all-or-none bursts when stimulated at hyperpolarized membrane potentials, with the same stimuli eliciting tonic firing at depolarized potentials. To the best of our knowledge, this report represents the first example of membrane potential state-dependent firing patterns in the OB. The ability of Golgi cells to fire repetitive low-threshold bursts at physiological sniffing frequencies suggests that these interneurons may effect rapid inhibition of GABAergic GCs during 
the onset of each inspiration cycle, transiently disinhibiting the primary output neurons of the $\mathrm{OB}$.

\section{Results}

We identified a subset of neurons with distinctive all-or-none bursts of action potentials as part of a survey of nongranule cells in the GCL of the rat OB. Six bursting cells with somata located in the GCL were filled with Alexa594 $(150 \mu \mathrm{M})$ through the patch clamp recording pipette and visualized using live 2photon imaging. Like Blanes cells, most of the dendritic arborization of bursting cells was contained within the GCL. By contrast, GCs typically generated a prominent apical dendrite that ramified in the external plexiform layer (Fig. 1A, left panel; see
A

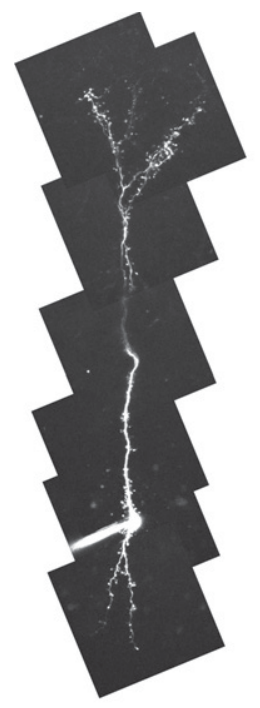

Granule Cell

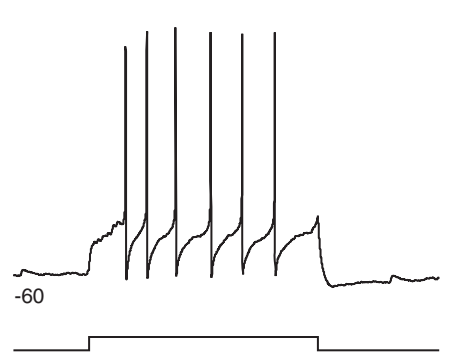

B

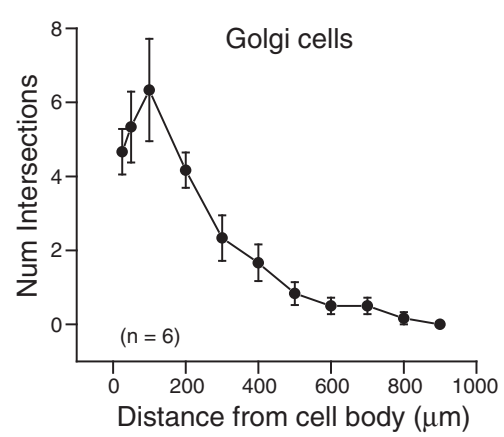

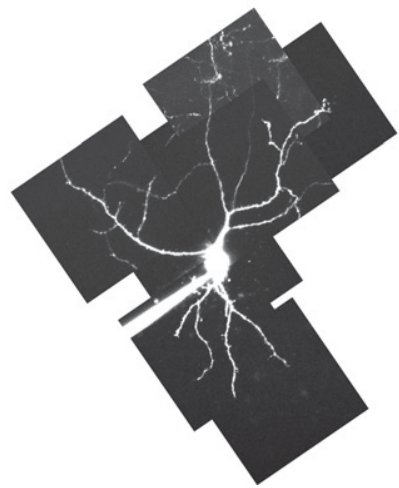

Blanes Cell

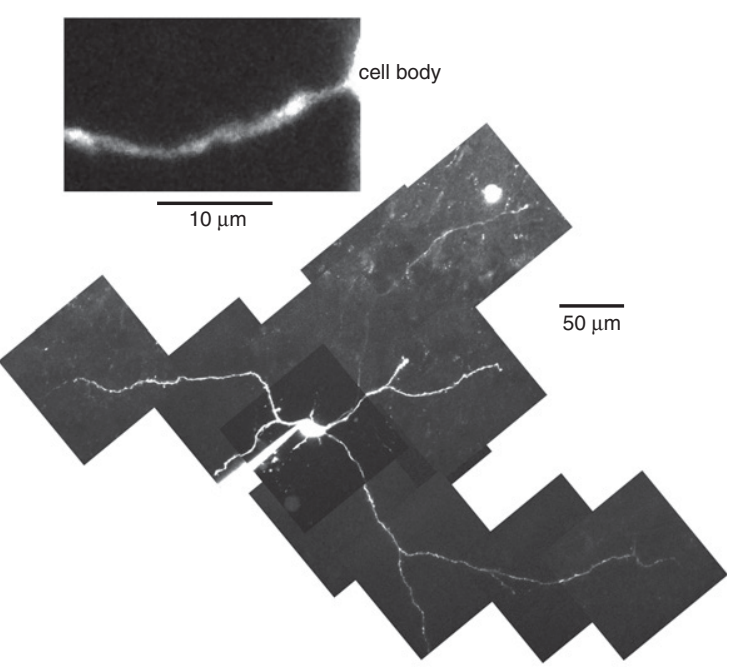

Golgi Cell

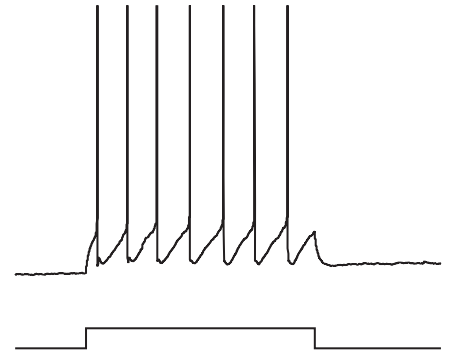

C

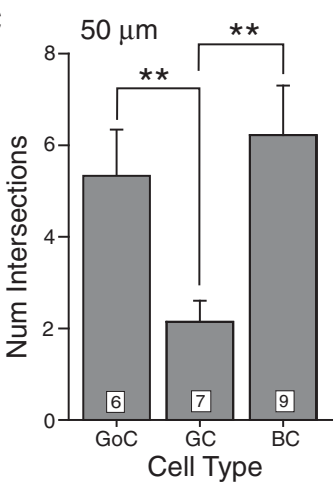

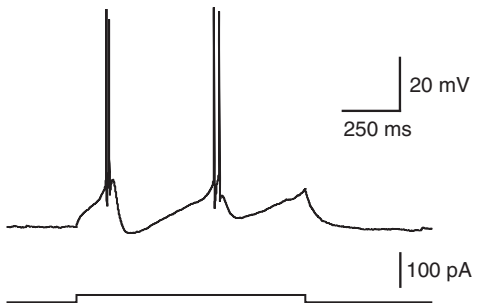

D

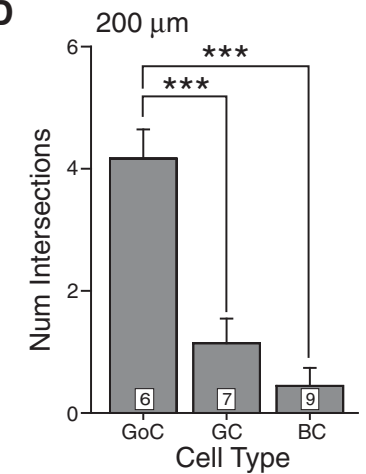

Figure 1. Morphology and intrinsic properties of neurons in the granule cell layer. ( $A$ ) Reconstructions of three different $G C L$ neurons recorded intracellularly and filled with Alexa594. Neurons were imaged in live brain slices using 2-photon microscopy. Image montages were created from multiple maximal Z-stack projections. Calibration bar represents $50 \mu \mathrm{m}$ in each montage and $10 \mu \mathrm{m}$ in the enlargement of the Golgi cell dendrite shown in the inset. Example response to 1-sec duration depolarizing steps are shown below each montage. The membrane potential at the beginning of each episode is indicated below trace. (B) Sholl analysis of dendritic arborization calculated from six Golgi cells. (C) Plot of the frequency of dendritic bifurcations from Sholl analysis $50 \mu \mathrm{m}$ from the cell body in Golgi cells $(\mathrm{GoC}, n=6)$, granule cells $(\mathrm{GC}, n=7)$, and Blanes cells $(\mathrm{BC}, n=9)$. $\left.{ }^{* *}\right) P<0.02$. $(D)$ Plot of frequency of dendritic bifurcations $200 \mu \mathrm{m}$ from the cell body in the same neuron classes. $\left.{ }^{* * *}\right) P<0.001$. Granule and Blanes cell reconstructions analyzed to compare with Golgi cells were obtained as part of a previous study (Pressler and Strowbridge 2006). 
Price and Powell 1970; Schneider and Macrides 1978; Pressler and Strowbridge 2006). The cell body of bursting GCL cells (204.3 \pm 24 $\left.\mu \mathrm{m}^{2}, n=6\right)$ was larger than both GCs $\left(47.4 \pm 8 \mu \mathrm{m}^{2}, n=8, P<\right.$ $0.0001)$ and Blanes cells $\left(117.7 \pm 12 \mu \mathrm{m}^{2}, n=9, P<0.005\right)$. Bursting GCL neurons had multiple primary dendrites emanating from the soma $(4.7 \pm 0.6)$ while GCs typically generate only one apical dendrite and 0-2 basal dendrites (Pressler and Strowbridge 2006). Sholl analysis of the dendritic arborization of bursting cell (Fig. 1B-D) also demonstrated significantly more dendritic branches $50 \mu \mathrm{m}$ from the cell body than GCs $(P<0.02)$ (Fig. 1C) and more branches $200 \mu \mathrm{m}$ from the cell body than either GCs or Blanes cell $(P<0.001)$ (Fig. 1D). The dendrites of bursting cells were either aspiny (two of six visualized bursting cells) or sparsely spiny (mean spine density $1.1 \pm 0.6$ per $100 \mu \mathrm{m}, n=4$ cells) (Fig. 1A, inset). By contrast, both Blanes cells and GCs are densely spiny (Price and Powell 1970; Schneider and Macrides 1978; Pressler and Strowbridge 2006). These morphological properties closely resemble the large, relatively aspiny GCL interneurons termed Golgi cells by Ramón y Cajal (1911) and others (Schneider and Macrides 1978; LopezMascaraque et al. 1986; Kosaka and Kosaka 2010), a terminology we adopted in this report.

In addition to morphological differences, action potentials in Golgi cells were different than those of the two other defined types of GCL neurons, Blanes and GCs. The amplitude of action potentials in Golgi cells $(61.4 \pm 4.1 \mathrm{~V}, n=13)$ was significantly less than in Blanes cells $(81.8 \pm 1.1 \mathrm{mV}, n=8, P<0.0001)$ and not different from GCs $(60.5 \pm 2.0, n=13, P>0.05)$ (Fig. 1A, bottom traces). The width of action potentials in Golgi cells ( $2.63 \pm$ 0.13 msec measured at threshold, $n=13$ ) was significantly greater than that of both Blanes cells ( $2.03 \pm 0.14 \mathrm{msec}, n=8, P<0.005)$ and granule cells $(2.08 \pm 0.05 \mathrm{msec}, n=13, P<0.0001)$. Action potential threshold in Golgi cells $(-32.7 \pm 1.4 \mathrm{mV})$ was intermediate between the very depolarized threshold of GCs $(-22.2 \pm$ $1.6 \mathrm{mV}, P<0.0001)$ and the relatively hyperpolarized action potential threshold of Blanes cells $(-39.9 \pm 1.4 \mathrm{mV}$, different from Golgi cells, $P<0.005)$.

Golgi cells also differed from Blanes cells and GCs in the type of afterpotential (AP) generated following action potential trains (Fig. 2A). Afterpotentials were assessed following depolarizing steps from similar membrane potentials (mean $-62.6 \mathrm{mV}$ for Golgi cells, $-61.8 \mathrm{mV}$ for GCs, and $-60.5 \mathrm{mV}$ for Blanes cells). Step amplitude was adjusted to evoke an average of $8-10$ spikes (mean 8.4 APs for Golgi cells, 9.4 APs for GCs, and 9.8 APs for Blanes cells over 1-sec duration steps) and the amplitude of the afterpotential was assayed at $500 \mathrm{msec}$ following step offset. As shown in Figure 2B, most Golgi cells did not generate afterpoten- tials under these conditions (mean amplitude $=0.00 \pm 0.49 \mathrm{mV}$, $n=10)$ while Blanes cells evoked large afterdepolarizations (5.17 $\pm 0.5 \mathrm{mV}$ amplitude, $n=17$, significantly different from Golgi cells, $P<0.0001$ ) and GCs evoked afterhyperpolarizations $(-2.16 \pm 0.4 \mathrm{mV}$ amplitude, $n=12, P<0.002$ from Golgi cells). The significant differences in afterpotential amplitude we found following standardized step responses suggests that different GCL cell types express distinctive constellations of intrinsic conductances.

Additionally, the input resistance of Golgi cells (728 $\pm 60 \mathrm{M} \Omega$, $n=13)$ was similar to GCs ( $789 \pm 88 \mathrm{M} \Omega, P>0.05)$ and was significantly higher than the input resistance of Blanes cells (313 \pm 48 $\mathrm{M} \Omega, P<0.0001)$. The resting membrane potential of Golgi cells $(-58.3 \pm 1.0 \mathrm{mV}, n=7)$ was significantly more depolarized than either Blanes cells $(-66.0 \pm 1.5 \mathrm{mV}, n=8, P<0.002)$ or GCs $(-67.3 \pm 2.2 \mathrm{mV}, n=9, P<0.005)$.

Olfactory bulb Golgi cells exhibit two distinct firing modes, tonic and bursting, that depended on membrane potential. In the example Golgi cell illustrated in Figure 3A, tonic firing was evoked by three different depolarizing step amplitudes from $-52 \mathrm{mV}$ and burst firing from $-70 \mathrm{mV}$. The initial bursts evoked by the depolarizing steps were stereotyped across responses (see below), though subsequent bursts tended to be prolonged with longer inter-spike intervals (cf. top burst-mode trace in Fig. 3A). Golgi cells appeared to be most sensitive to prolonged depolarizations, such as the 1-sec duration steps shown in Figure $3 \mathrm{~A}$, in the tonic firing mode; weak depolarizing steps (10 pA) that evoked multiple action potentials from $-52 \mathrm{mV}$ typically failed to trigger spikes when the Golgi cell was held at $-70 \mathrm{mV}$. A switch between tonic and burst firing modes upon hyperpolarization, as shown in Figure 3A, was observed in seven out of seven Golgi cells in which membrane potential was varied systematically. The average membrane potential in which depolarizing steps evoked tonic firing was $-53.0 \pm 0.7 \mathrm{mV}(n=23)$ while burst firing was evoked in the same cells at $-65.1 \pm 0.4 \mathrm{mV}(n=135$, significantly different, $P<0.0001$ ) (Fig. 3B). Nine out of 13 Golgi cells tested generated multiple bursts in response to 1 -sec duration depolarizing steps. The mean inter-burst interval in these nine cells was $334 \pm 10$ msec. The range of intervals (90\% of intervals between 1.8 and $5.1 \mathrm{~Hz}$ ) (Fig. 3C) was similar to inter-sniff intervals observed in awake rodents (Fukunaga et al. 2012), raising the possibility that burst responses in Golgi cells could be entrained by normal inspiration rhythms.

We performed a set of experiments to define the mechanism of these burst responses. Burst responses in Golgi cells were unaffected by blockade of fast glutamatergic synaptic transmission (Fig. 4A), suggesting that they were mediated by intrinsic conductances rather than excitatory synaptic feedback input. Bursts also could be triggered reliably by both depolarizing stimuli (13 out of 13 Golgi cells) (Figs. 1-3) and during rebound responses following hyperpolarizing steps (10 out of 11 Golgi cells tested) (Fig. 4B,C). The latency to rebound bursts decreased as the amplitude of the hyperpolarizing step increased (Fig. 4C), suggesting that hyperpolarization facilitated burst responses. The inter-spike intervals within Golgi cell burst responses were clustered at very short times (most $<20$ msec) (Fig. 4D) and the average burst inter-spike interval was $19.3 \pm 1.5 \mathrm{msec}$ (Fig. 4D, inset). Most all-or-none bursts in Golgi cells typically consisted of two or three action potentials (mean $2.4 \pm 0.05$ spikes, $n=113$ bursts).
A

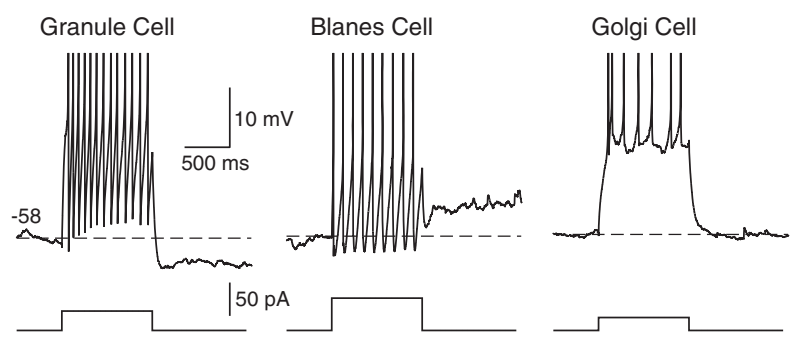

Figure 2. Afterpotentials associated with different granule cell layer neuron types. $(A)$ Example responses to depolarizing current steps in three types of GCL neurons. Action potentials truncated. (B) Plot of afterpotential amplitude assayed 500 msec following step offset. Number of cells tested are indicated within each bar. Golgi cells did not generate an afterpotential to the standardized depolarizing test stimulus (mean amplitude $0.0 \mathrm{mV}, n=10$ cells). (**) $P<0.002$, (***) $P<0.0001$.

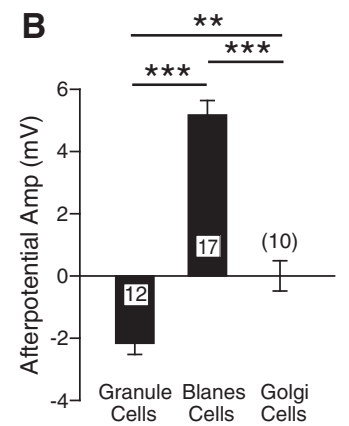

www.learnmem.org 
A

Tonic Mode
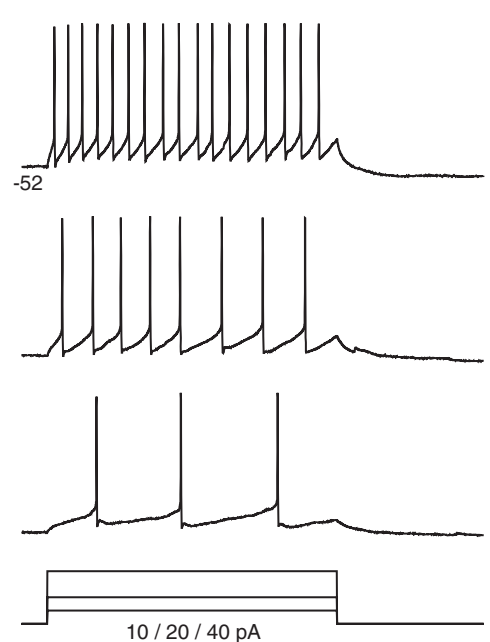

$10 / 20 / 40 \mathrm{pA}$

B

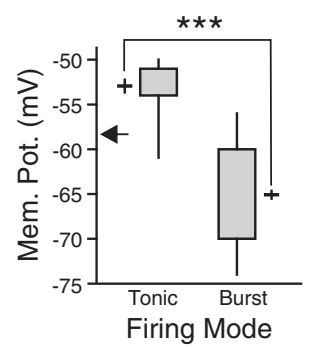

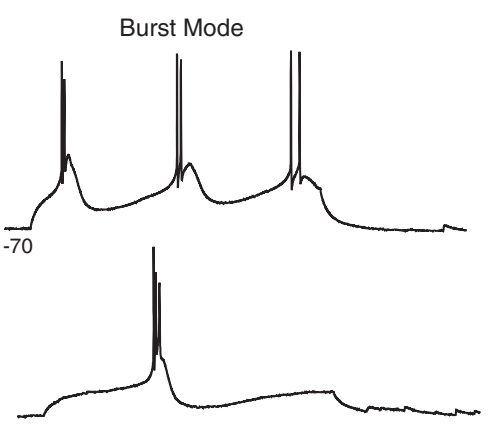

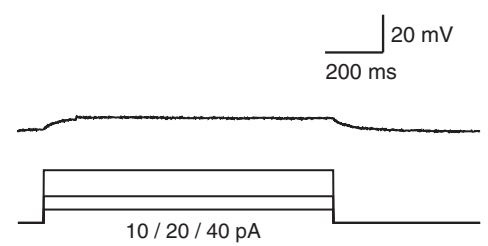

C

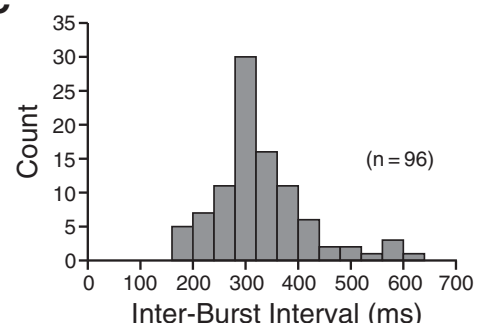

Figure 3. Voltage-dependent burst responses in Golgi cells. $(A)$ Responses to the same series of graded depolarizing current steps at two different membrane potentials in one Golgi cell. (B) Plot of firing mode (bursting or tonic firing) associated with different membrane potentials in recordings from 13 Golgi cells. Vertical lines indicate range over all membrane potentials, and filled rectangles represent $95 \%$ confidence intervals of the mean. The membrane potential mean \pm SEM for each firing mode over 13 Golgi cells is plotted outside filled rectangles. The average resting potential of Golgi cells without added bias current is indicated by horizontal arrow inside $Y$ axis. $(* * *) P<0.0001$. (C) Histogram of intervals between bursts in trials in which depolarizing current steps triggered more than one burst response. pulses resembled burst responses evoked by 1 -sec duration steps (Fig. 5D, inset). In three of five Golgi cells tested, nickel completely blocked regenerative depolarizing responses triggered by shortduration current pulses, as illustrated in Figure 5C. In the remaining Golgi cell, nickel attenuated but did not eliminate regenerative depolarizing responses (Fig. $5 \mathrm{D})$, suggesting that additional voltagegated conductances can contribute to burst responses.

Finally, we asked if burst responses were triggered in response to phasic depolarizing stimuli that mimic the rhythmic sensory drive the olfactory bulb normally receives during normal respiration and active sniffing (Cang and Isaacson 2003; Fukunaga et al. 2012). Graded $\alpha$-function current stimuli (Balu et al. 2004) evoked all-or-none burst responses in eight of eight Golgi cells tested. Varying the stimulus amplitude modulated burst latency but did not affect the burst response itself (Fig. 6A). Sequences of $\alpha$-function current stimuli typically triggered bursts only on the first response in the train with weaker responses, containing fewer spikes, evoked by later stimuli (Fig. 6A). A similar pattern of response adaption to trains of current pulses was observed when Golgi cells were held at hyperpolarized membrane potentials (Fig. 6B). By contrast, responses to the same train of current pulses applied at depolarized membrane potentials were reliable and did not adapt (Fig. 6B, inset). These results demonstrate that adaptation to phasic stimuli in Golgi cells is dependent on membrane potential.
The rebound bursting seemed reminiscent of the classic lowthreshold Ca current response in thalamacortical cells, so in this set of experiments we tested the involvement of these channels. The inorganic calcium channel antagonist nickel (Hille 2001) diminished or abolished burst responses in Golgi cells. As shown in Figure 5A, bath application of 100-200 $\mu \mathrm{M}$ nickel abolished single (four of five cells) and repetitive bursts (two of two Golgi cells with repetitive bursts), arguing that voltage-gated calcium current contributes to these all-or-none intrinsic responses. Nickel also blocked rebound bursts in five of five Golgi cells tested. Rebound bursts were suppressed by nickel when tested over a range of hyperpolarizing step amplitudes that exceeded the amplitude of step responses in control conditions (Fig. 5B). In two of five Golgi cells tested, rapid spike doublets (inter-spike intervals $<20 \mathrm{msec}$ ) remained in nickel even though the depolarizing burst envelope was blocked, arguing that rapid spike discharges are mediated, at least in part, by conductances that are resistant to nickel-sensitive $\mathrm{Ca}^{2+}$ channels.

All-or-none burst responses also could be triggered by shortduration depolarizing steps (Fig. 5C,D). Under these conditions, the depolarizing envelope associated with the burst continued beyond the current step stimulus, consistent with intrinsic responses mediated by regenerative inward conductances (Llinás and Jahnsen 1982). Bursts triggered by short-duration current

\section{Discussion}

Although previous studies have established a large diversity of neurons in the GCL by examining morphological properties and immunoreactivity to calcium binding proteins, little is known about the functional properties of interneurons in this layer. Here, we identify a homogeneous subpopulation of bursting interneurons whose dendritic morphology is consistent with Golgi cells-a cell type described in classic anatomical studies defined by long whip-like dendrites and a paucity of dendritic spines (Ramón y Cajal 1911; Price and Powell 1970; Schneider and Macrides 1978; Kosaka and Kosaka 2010). We find that Golgi cells are capable of responding to depolarizing stimuli in two modes (tonic and burst firing) that depend on membrane potential and resemble the firing properties commonly associated with thalamic relay cells (Llinás and Jahnsen 1982) We believe that this is the first demonstration of neurons with dual phasic/tonic firing modes in the olfactory bulb.

Using the Golgi method, Ramón y Cajal (1911) described granule cells and three primary nongranule cell types with somata located in the granule cell layer. Subsequent anatomical studies employing immunocytochemical methods (Schneider and Macrides 1978; Lopez-Mascaraque et al. 1986; Kakuta et al. 1998; Alonso et al. 2001; Kosaka and Kosaka 2010) expanded 

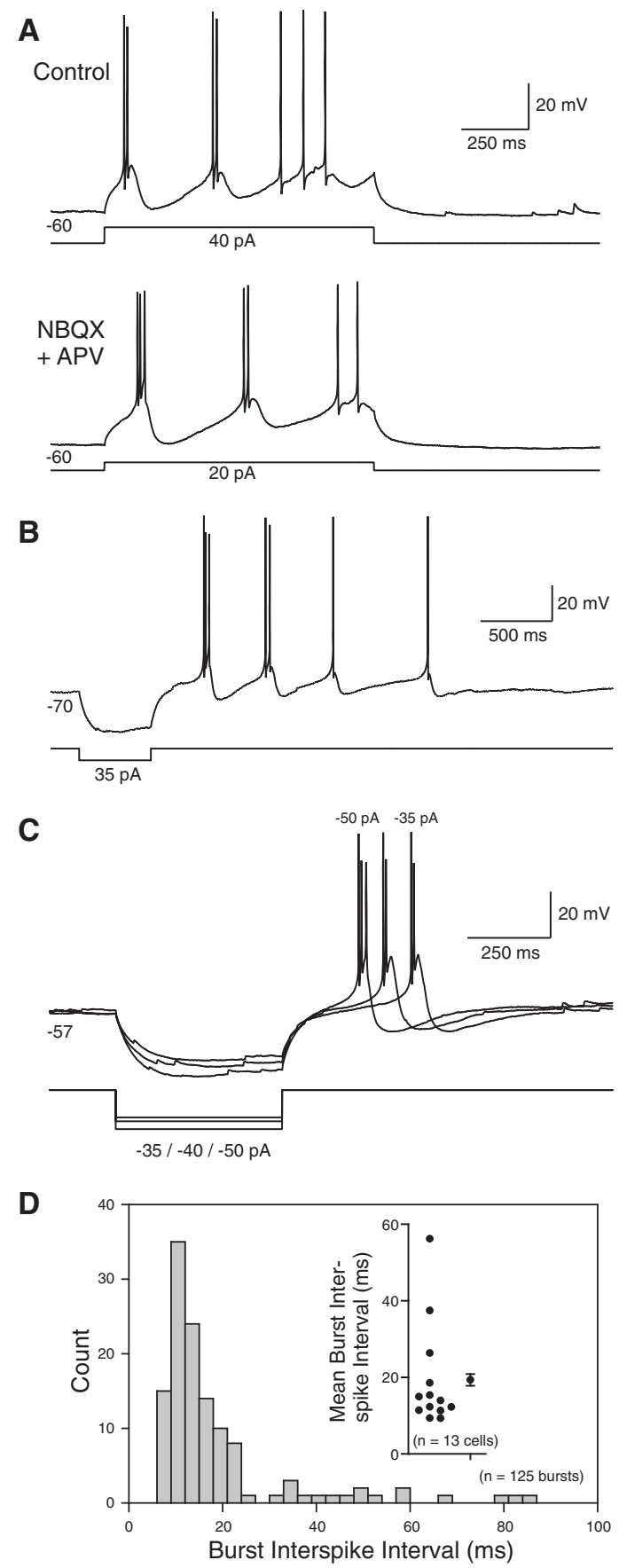

Figure 4. Properties of Golgi cell burst responses. $(A)$ Responses to depolarizing current steps before and after bath application of ionotropic glutamatergic receptor antagonists NBQX $(5 \mu \mathrm{M})$ and D-APV $(25 \mu \mathrm{M})$. (B) Example of repetitive burst responses triggered by a single hyperpolarizing current step. (C) All-or-none burst rebound responses triggered by graded hyperpolarizing current steps. (D) Histogram of inter-spike intervals within all-or-none bursts from 13 Golgi cells. (Inset) Distribution of burst inter-spike intervals in each Golgi cell analyzed. Overall mean \pm SEM plotted to the right of the scatter plot.

the inventory of nongranule GCL cells to seven types (Blanes cells, Golgi cells, vertical cells of Cajal, horizontal cells, bi-tufted neurons, deep stellate cells, and deep short-axon cells). We previously defined the electrophysiological properties of the Blanes cell (Pressler and Strowbridge 2006), a spiny multipolar cell capable of generating sustained periods of action potential firing in response to a brief stimulus. Golgi cells are also multipolar cells, like Blanes cells, but their dendrites are almost completely devoid of spines (see Fig 1; Ramón y Cajal 1911; Schneider and Macrides 1978; Lopez-Mascaraque et al. 1986; Pressler and Strowbridge 2006), and their dendrites appear to extend farther in the granule cell layer (see Fig. 1; Ramón y Cajal 1911; Schneider and Macrides 1978; Eyre et al. 2008). Additionally, the majority of the neuronal processes in our reconstructed Blanes and Golgi cells were maintained within the granule cell layers (and see Price and Powell 1970; Schneider and Macrides 1978; Scott et al. 1987; Nakajima et al. 1996; Kakuta et al. 1998; Kosaka and Kosaka 2010).

We did not determine the neurotransmitter phenotype of Golgi cells in this study. However, previous work from Kosaka and Kosaka (2010) demonstrated that Golgi cells in the mouse OB strongly express calbindin D28k (see Fig. 2), and GraciaLlanes and colleagues (2003) showed that calbindin positive cells in the rat GCL are GABAergic (see Fig. 5). Based on these published results, Golgi cells are likely to be inhibitory interneurons. Reconstructions of Golgi-stained Golgi cells also suggest that these interneurons innervate GCs (Price and Powell 1970; Schneider and Macrides 1978; Gracia-Llanes et al. 2003; Eyre et al. 2008; Kosaka and Kosaka 2011), though future studies will be required to explore other potential synaptic targets of Golgi cells.

Eyre and colleagues (Eyre et al. 2008, 2009) described deep short-axon cells that are morphologically similar to Golgi cells in this report (see Fig. 2A in Eyre et al. 2008). These studies demonstrate that at least some short-axon cells in the GCL are GABAergic and synapse onto granule cells, consistent with other anatomical studies of GCL interneurons (Price and Powell 1970; Gracia-Llanes et al. 2003). While the electrophysiological component study of Eyre et al. (2008) was focused on miniature synaptic potentials and action potential-related properties, the tonic firing in the two step responses presented (insets in their Figs 1B and 2A) are consistent with the firing responses we observe at depolarized membrane potentials. Neither of the Eyre et al. (2008) short-axon cell studies examined the effect of changing the membrane potential on firing properties.

Golgi cells represent the clearest example, to our knowledge, of state-dependent firing modes in the olfactory bulb. External tufted cells are glutamatergic neurons that appear to receive direct sensory input from olfactory receptor neurons (Hayar et al. 2004b; Gire et al. 2012) and project to tertiary olfactory structures. Both mitral and tufted cells, the principal neurons in the OB, fire intermittently to prolonged depolarizing step current stimuli (Balu et al. 2004). External tufted cells, like Golgi cells, can fire bursts of action potentials but lack a tonic firing mode (Hayar et al. 2004a,b, 2005). While granule cells express low-threshold $\mathrm{Ca}^{2+}$ current (Egger et al. 2005; Egger 2008), classic all-or-none lowthreshold bursts of action potentials are only infrequently observed in these interneurons. Future studies will be required to determine if the large difference in intrinsic properties between OB granule and Golgi cells relates primarily to the level of LVA $\mathrm{Ca}^{2+}$ channel expression, the spatial location of these channels, and/or the presence of outward currents in GCs that inhibit all-or-none LVA-mediated bursts.

\section{Mechanism of bursting activity}

Several lines of evidence suggest that burst responses in Golgi cells are generated through intrinsic, rather than synaptic, conductances. We find that both depolarizing and hyperpolarizing steps can trigger similar action potential bursts, suggesting that bursts do not originate from feedback synaptic circuits. Consistent 

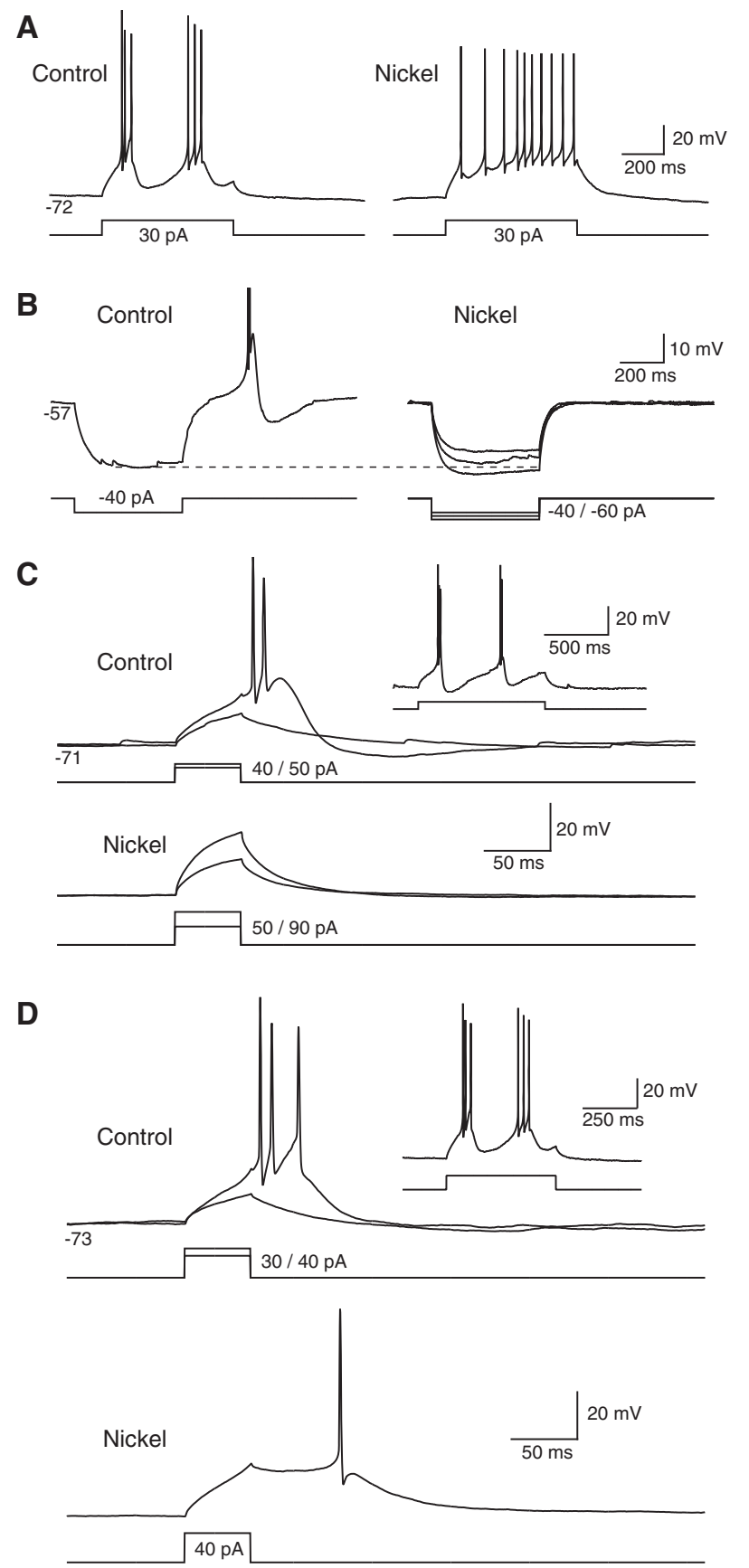

Figure 5. Attenuation of Golgi cell burst responses by nickel. $(A)$ Responses to the same depolarizing step response before and after bath application of nickel. (B) Nickel $(100-200 \mu \mathrm{M})$ blocked rebound bursts triggered by hyperpolarizing steps. (C) Burst response triggered by shortduration $(50 \mathrm{msec}$ ) depolarizing current step. Spiking associated with burst response occurred after current step. Nickel blocked both regenerative depolarizing envelope and spiking associated with burst response. (D) Effect of nickel in a different Golgi cell. While nickel blocked spiking associated with the burst response, nickel did not eliminate regenerative depolarization which was maintained following step offset. Response to 1 -sec duration current step in control conditions shown in inset.

with this result is the observation that blockade of ionotropic glutamate receptors with APV and NBQX did not abolish burst responses. Unlike bursting external tufted cells (Hayar et al. 2004a,b), Golgi cells do not fire bursts spontaneously.
Both the low threshold for triggering all-or-none bursts at hyperpolarized membrane potentials and the membrane potential state-dependent firing patterns observed in Golgi cells (e.g., tonic firing at depolarized potentials with burst responses triggered by depolarizing steps at hyperpolarized voltages) are well-known characteristics of thalamic relay cells (Llinás and Jahnsen 1982). As with thalamic cells, the inorganic T-type calcium channel blocker nickel (Lee et al. 1999) selectively attenuates all-or-none bursting without abolishing the tonic firing mode, suggesting that much of the burst response depolarizing envelope reflects low-threshold voltage-gated $\mathrm{Ca}^{2+}$ current. The established actions of nickel on ionic channels, including high-threshold $\mathrm{Ca}^{2+}$ channels, and the absence of highly selective organic blockers of LVA $\mathrm{Ca}^{2+}$ channels make it difficult to completely define the role of T-type $\mathrm{Ca}^{2+}$ currents in this response.
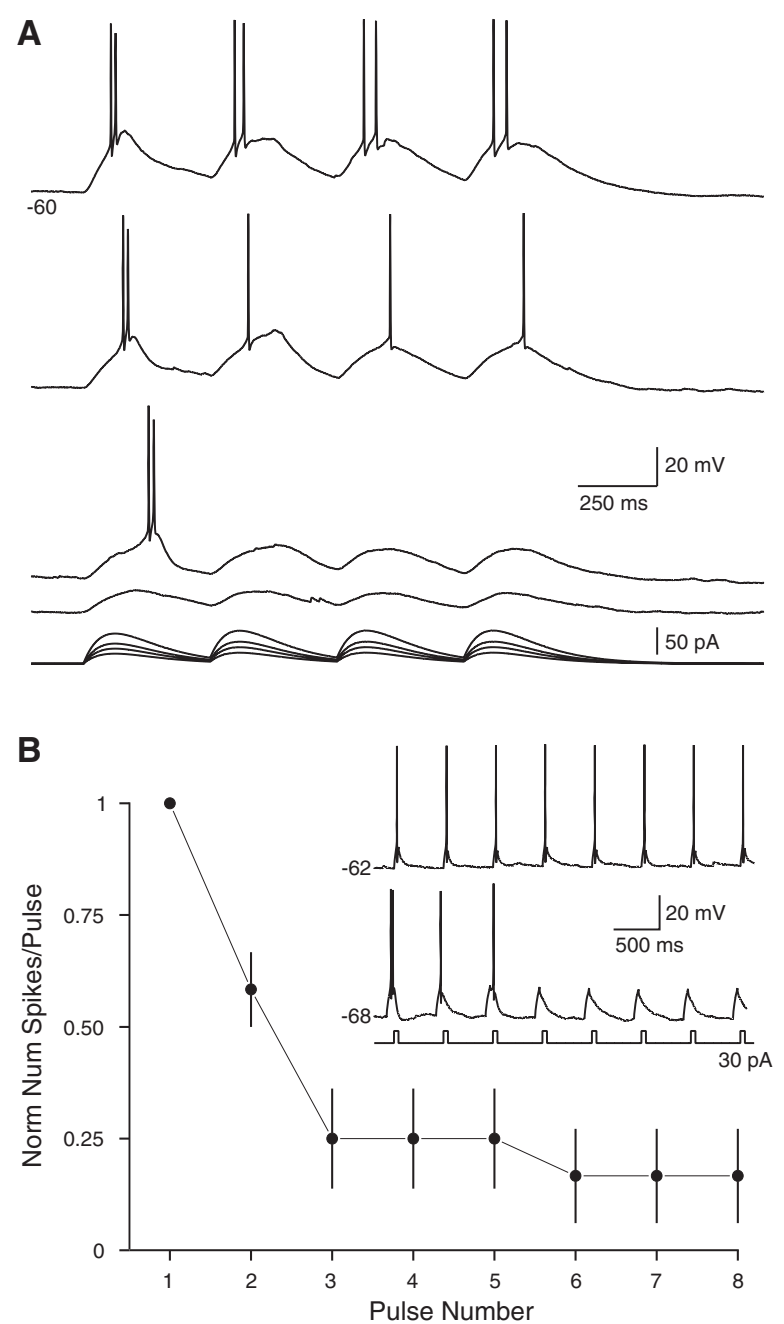

Figure 6. Voltage-dependent adaptation to phasic stimuli. $(A) \mathrm{Re}-$ sponses to trains of $\alpha$-function of graded amplitude in a Golgi cell. Bursts were reliably triggered only by the first $\alpha$-function stimulus and burst latency was modulated by stimulus amplitude. (B) Plot of number of action potentials evoked by each current pulse in a train of eight pulses at $-68 \mathrm{mV}$. The number of spikes in each response was normalized to the number of spikes evoked by the first pulse in each train. Mean \pm SEM plotted for six repetitions of the same stimulus train. (Inset) Responses to a single train at $-68 \mathrm{mV}$, illustrating burst adaptation. Responses to current pulses presented at $-62 \mathrm{mV}$ triggered single-spike responses that did not adapt. 
Based on the analogy with state-dependent firing patterns in thalamic neurons, we hypothesize that firing mode in Golgi cells is controlled dynamically by neuromodulators, likely through centrifugal input pathways to $\mathrm{OB}$ that often terminate in the GCL (Shepherd 2004). In the thalamus, acetylcholine (ACh) along with norepinephrine (NE) and serotinin (5-HT) play central roles in depolarizing the resting membrane potential of relay neurons during transitions from slow wave sleep to wakefulness (Steriade and Deschenes 1984), shifting the predominant firing pattern from bursts to tonic firing as T-type $\mathrm{Ca}^{2+}$ channels become inactivated. Centrifugal modulatory pathways may regulate the firing mode of Golgi cells to provide fast, sniff-locked inhibition of GCs when Golgi cells are hyperpolarized and sustained inhibition of GCs during excitatory barrages that depolarize both Golgi and granule cells. Muscarinic receptor stimulation promotes persistent firing in GCs (Pressler et al. 2007) and may also lead to coordinated depolarization of Golgi cells and persistent inhibition of GCs necessary to prevent output saturation.

\section{Functional significance of Golgi cells in the olfactory bulb circuit}

The unusual dual firing mode we find in Golgi cells presumably enables them to play different roles in controlling granule cell function, depending on their resting membrane potential. At hyperpolarizing membrane potentials, low-threshold $\mathrm{Ca}^{2+}$ current likely functions to amplify sensory-driven synaptic excitation, triggering all-or-none bursts of action potentials in Golgi cells and summating IPSPs in postsynaptic granule cells. Inhibitory postsynaptic currents triggered by bursting Golgi cells are likely to be well suited to provide rapid, time-locked inhibition of GCs, presumably delaying GC activation. One function of this inhibition may be to provide a defined time window for sensory input to directly control spiking in mitral and tufted cells before inhibition from GCs begins to sculpt principal cell output. We found that Golgi cells are well adapted to fire repetitive lowthreshold bursts at frequencies similar to rodent sniffing rates (Charpak et al. 2001), suggesting that this transient mitral cell/ tufted cell disinhibition function could be sustained over multiple inhalation cycles. At depolarized membrane potentials, Golgi cells will provide graded inhibition onto granule cells that varies in proportion to the excitatory input and could potentially last throughout the sniff cycle. Thus, the function of Golgi cells could dynamically change from divisive inhibition when Golgi cells are hyperpolarized, and presumably fire bursts at the start of sniff cycles, to subtractive inhibition when Golgi cells are depolarized and fire tonically in proportion to excitatory synaptic drive. While we did not determine the source of excitatory synaptic drive to Golgi cells in this study, these interneurons are likely to receive indirect sensory input, relayed via mitral and tufted cells, since axon collaterals of both OB principal cell types ramify in the GCL (containing most of the Golgi cell dendritic arborization; Shepherd 2004).

A second, related function of nongranule cells in the GCL, such as Golgi and Blanes cells, may be to create diversity in granule cell responses to similar sensory inputs. Recent work in a cerebellum-like structure in the electric fish suggest that diverse intrinsic properties of local circuit neurons may function to expand the repertoire of granule cell responses to stereotyped inputs (Requarth and Sawtell 2011). The resulting large population of granule cell responses enables that brain region to efficiently generate "negative images" of sensory input which could be subtracted at the next cell layer, yielding derivative-like neural signals that emphasize the unexpected components of the sensory response. While there is a large excess of granule cells, relative to principal neurons, in both the $\mathrm{OB}$ and cerebellum, whether OB GCs gener- ate a similar wide range of responses to simple olfactory stimuli remains to be determined.

\section{Materials and Methods}

Olfactory bulb slices (300 $\mu \mathrm{m}$ thick) from P14-25 Sprague-Dawley rats of either sex were prepared using a Leica VT1000 or VT1200 vibratome as previously described (Pressler and Strowbridge 2006). An artificial cerebrospinal fluid (ACSF) solution with low $\left[\mathrm{Ca}^{2+}\right]$ was used when preparing and storing slices that contained (in mM): $124 \mathrm{NaCl}, 2.6 \mathrm{KCl}, 1.23 \mathrm{NaH}_{2} \mathrm{PO}_{4}, 3 \mathrm{MgSO}_{4}, 26 \mathrm{NaHCO}_{3}$, 10 dextrose, $1 \mathrm{CaCl}_{2}$, equilibrated with $95 \% \mathrm{O}_{2} / 5 \% \mathrm{CO}_{2}$. The ACSF was chilled to $4^{\circ} \mathrm{C}$ during slicing. Olfactory bulb slices were incubated in a $30^{\circ} \mathrm{C}$ water bath for $30 \mathrm{~min}$ and then maintained at room temperature. During experiments, olfactory bulb slices were superfused with ACSF that contained (in mM): 124 $\mathrm{NaCl}, 3 \mathrm{KCl}, 1.23 \mathrm{NaH}_{2} \mathrm{PO}_{4}, 1.2 \mathrm{MgSO}_{4}, 26 \mathrm{NaHCO}_{3}, 10$ dextrose, $2.5 \mathrm{CaCl}_{2}$, equilibrated with $95 \% \mathrm{O}_{2} / 5 \% \mathrm{CO}_{2}$ and warmed to $30^{\circ} \mathrm{C}$. Except where noted, all compounds used in this study were obtained from Sigma. Glutamate receptor antagonists (NBQX and APV) were purchased from Tocris.

Whole-cell current-clamp recordings were made from granule cell layer neurons visualized with infrared-differential interference contrast (IR-DIC) optics using either Axioskop 1 FS (Carl Zeiss) or BW51WI (Olympus) fixed-stage upright microscopes and Axopatch 1D amplifier (Molecular Devices). Electrodes used for whole-cell recordings (5-7 M 2 ) were pulled from thin-wall capillary tubes with filament (1.2 mm OD, WPI) and contained (in $\mathrm{mM}$ ): $140 \mathrm{~K}$-methylsulfate, $4 \mathrm{NaCl}, 10$ HEPES, 0.2 EGTA, 4 MgATP, $0.3 \mathrm{Na}_{3} \mathrm{GTP}, 10$ phosphocreatine. The same internal solution was used for current-clamp recordings in a previous study of olfactory bulb interneurons (Pressler and Strowbridge 2006). In some experiments, Alexa594 (150 $\mu \mathrm{M}$, Invitrogen) was added to the internal solution to visualize the recorded neuron. Live imaging experiments were performed using a custom 2-photon microscope based on the Verdi V10 pump laser, Mira 900 Ti-sapphire laser (both from Coherent), and a high-speed XY galvanometer mirror set (6210, Cambridge Technology). Intracellularly loaded Alexa594 were excited at $830 \mathrm{~nm}$ through a $60 \times$ water immersion objective (Olympus). Emitted light was detected through a light path that included a 700DCLPXR dichroic mirror, a BG39 emission filter (both from Chroma Technology), and a cooled PMT detector module (H7422P-40, Hamamastu), as previously described (Pressler and Strowbridge 2006). In most experiments, the output of the Mira laser was attenuated by $>90 \%$ using a computer-controlled Pockels cell (ConOptics).

Intracellular recordings were low-pass filtered at $2 \mathrm{kHz}$ and sampled at $5 \mathrm{kHz}$ using a 16-bit analog-to-digital converter (ITC18, Instrutech/Heka) using custom software written in Visual Basic.NET (Microsoft) and Matlab (Mathworks). Origin 8.5 (OriginLab) and custom Matlab routines were used to analyze data. Pharmacological agents were applied by switching the perfusion solution. Voltages presented are not corrected for the liquid junction potential. Statistical significance was determined using the Student's $t$-test. Data are presented as mean \pm S.E.M.

\section{Acknowledgments}

We thank Isaac Youngstrom for helpful comments on this manuscript. This study was supported by NIH grant R01-DC04285 to B.W.S.

\section{References}

Alonso JR, Briñón JG, Crespo C, Bravo IG, Arévalo R, Aijón J. 2001. Chemical organization of the macaque monkey olfactory bulb: II. Calretinin, calbindin D-28k, parvalbumin, and neurocalcin immunoreactivity. J Comp Neurol 432: 389-407.

Aungst JL, Heyward PM, Puche AC, Karnup SV, Hayar A, Szabo G Shipley MT. 2003. Centre-surround inhibition among olfactory bulb glomeruli. Nature 426: 623-629. 
Balu R, Strowbridge BW. 2007. Opposing inward and outward conductances regulate rebound discharges in olfactory mitral cells. J Neurophysiol 97: 1959-1968.

Balu R, Larimer P, Strowbridge BW. 2004. Phasic stimuli evoke precisely timed spikes in intermittently discharging mitral cells. J Neurophysiol 92: $743-753$.

Cang J, Isaacson JS. 2003. In vivo whole-cell recording of odor-evoked synaptic transmission in the rat olfactory bulb. J Neurosci 23: $4108-4116$.

Charpak S, Mertz J, Beaurepaire E, Moreaux L, Delaney K. 2001. Odor-evoked calcium signals in dendrites of rat mitral cells. Proc Natl Acad Sci 98: 1230-1234.

Egger V. 2008. Synaptic sodium spikes trigger long-lasting depolarizations and slow calcium entry in rat olfactory bulb granule cells. Eur J Neurosci 27: 2066-2075

Egger V, Svoboda K, Mainen ZF. 2005. Dendrodendritic synaptic signals in olfactory bulb granule cells: Local spine boost and global low-threshold spike. J Neurosci 25: 3521-3530.

Eyre MD, Antal M, Nusser Z. 2008. Distinct deep short-axon cell subtypes of the main olfactory bulb provide novel intrabulbar and extrabulbar GABAergic connections. J Neurosci 28: 8217-8229.

Eyre MD, Kerti K, Nusser Z. 2009. Molecular diversity of deep short-axon cells of the rat main olfactory bulb. Eur J Neurosci 29: 1397-1407.

Ezeh PI, Wellis DP, Scott JW. 1993. Organization of inhibition in the rat olfactory bulb external plexiform layer. J Neurophysiol 70: 263-274.

Fukunaga I, Berning M, Kollo M, Schmaltz A, Schaefer AT. 2012. Two distinct channels of olfactory bulb output. Neuron 75: 320-329.

Gire DH, Franks KM, Zak JD, Tanaka KF, Whitesell JD, Mulligan AA, Hen R, Schoppa NE. 2012. Mitral cells in the olfactory bulb are mainly excited through a multistep signaling path. J Neurosci 32: 2964-2975.

Giridhar S, Doiron B, Urban NN. 2011. Timescale-dependent shaping of correlation by olfactory bulb lateral inhibition. Proc Natl Acad Sci 108: $5843-5848$.

Gracia-Llanes FJ, Crespo C, Blasco-Ibáñez JM, Marqués-Marí AI, Martínez-Guijarro FJ. 2003. VIP-containing deep short-axon cells of the olfactory bulb innervate interneurons different from granule cells. Eur J Neurosci 18: 1751-1763.

Hayar A, Karnup S, Shipley MT, Ennis M. 2004a. Olfactory bulb glomeruli: External tufted cells intrinsically burst at $\theta$ frequency and are entrained by patterned olfactory input. J Neurosci 24: 1190-1199.

Hayar A, Karnup S, Ennis M, Shipley MT. 2004b. External tufted cells: A major excitatory element that coordinates glomerular activity. J Neurosci 24: 6676-6685.

Hayar A, Shipley MT, Ennis M. 2005. Olfactory bulb external tufted cells are synchronized by multiple intraglomerular mechanisms. J Neurosci 25: $8197-8208$.

Hille B. 2001. Ion channels of excitable membranes. Sinauer Associates, Sunderland, MA.

Isaacson JS, Strowbridge BW. 1998. Olfactory reciprocal synapses: Dendritic signaling in the CNS. Neuron 20: 749-761.

Kakuta S, Oda S, Takayanagi M, Kishi K. 1998. Parvalbumin immunoreactive neurons in the main olfactory bulb of the house musk shrew, Suncus murinus. Brain Behav Evol 52: 285-291.

Kawaguchi Y, Kubota Y. 1997. GABAergic cell subtypes and their synaptic connections in rat frontal cortex. Cereb Cortex 7: 476-486.

Kay LM, Laurent G. 1999. Odor- and context-dependent modulation of mitral cell activity in behaving rats. Nat Neurosci 2: 1003-1009.
Kosaka T, Kosaka K. 2010. Heterogeneity of calbindin-containing neurons in the mouse main olfactory bulb: I. General description. Neurosci Res 67: $275-292$.

Kosaka T, Kosaka K. 2011. "Interneurons" in the olfactory bulb revisited. Neurosci Res 69: 93-99.

Lee JH, Gomora JC, Cribbs LL, Perez-Reyes E. 1999. Nickel block of three cloned T-type calcium channels: Low concentrations selectively block $\alpha 1$ H. Biophys J 77: 3034-3042.

Liu S, Plachez C, Shao Z, Puche A, Shipley MT. 2013. Olfactory bulb short axon cell release of GABA and dopamine produces a temporally biphasic inhibition-excitation response in external tufted cells. J Neurosci 33: 2916-2926.

Llinás R, Jahnsen H. 1982. Electrophysiology of mammalian thalamic neurones in vitro. Nature 297: 406-408.

Lopez-Mascaraque L, De Carlos JA, Valverde F. 1986. Structure of the olfactory bulb of the hedgehog (Erinaceus europaeus): Description of cell types in the granular layer. J Comp Neurol 253: $135-152$.

Mori K, Nagao H, Yoshihara Y. 1999. The olfactory bulb: Coding and processing of odor molecule information. Science 286: 711-715.

Nakajima T, Okamura M, Ogawa K, Taniguchi K. 1996. Immunohistochemical and enzyme histochemical characteristics of short axon cells in the olfactory bulb of the golden hamster. J Vet Med Sci 58: 903-908.

Pressler RT, Strowbridge BW. 2006. Blanes cells mediate persistent feedforward inhibition onto granule cells in the olfactory bulb. Neuron 49: 889-904.

Pressler RT, Inoue T, Strowbridge BW. 2007. Muscarinic receptor activation modulates granule cell excitability and potentiates inhibition onto mitral cells in the rat olfactory bulb. J Neurosci 27: 10969-10981.

Price JL, Powell TP. 1970. The mitral and short axon cells of the olfactory bulb. J Cell Sci 7: 631-651.

Ramón y Cajal S. 1911. Histologie du systeme nerveux de 1'homme et des vertebres. Maloine, Paris.

Requarth T, Sawtell NB. 2011. Neural mechanisms for filtering self-generated sensory signals in cerebellum-like circuits. Curr Opin Neurobiol 21: 602-608.

Schneider SP, Macrides F. 1978. Laminar distributions of interneurons in the main olfactory bulb of the adult hamster. Brain Res Bull 3: 73-82.

Scott JW, McDonald JK, Pemberton JL. 1987. Short axon cells of the rat olfactory bulb display NADPH-diaphorase activity, neuropeptide Y-like immunoreactivity, and somatostatin-like immunoreactivity. J Comp Neurol 260: 378-391.

Shepherd GM. 2004. The synaptic organization of the brain. Oxford University Press, Oxford, UK.

Somogyi P, Tamás G, Lujan R, Buhl EH. 1998. Salient features of synaptic organisation in the cerebral cortex. Brain Res Brain Res Rev 26: $113-135$.

Stepanyants A, Tamás G, Chklovskii DB. 2004. Class-specific features of neuronal wiring. Neuron 43: 251-259.

Steriade M, Deschenes M. 1984. The thalamus as a neuronal oscillator. Brain Res 320: 1-63.

Received May 15, 2013; accepted in revised form June 12, 2013. 


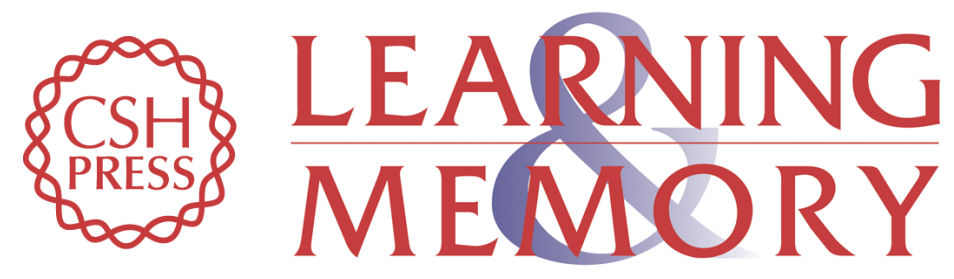

\title{
Voltage-dependent intrinsic bursting in olfactory bulb Golgi cells
}

\author{
R. Todd Pressler, Peter A. Rozman and Ben W. Strowbridge
}

Learn. Mem. 2013, 20:

Access the most recent version at doi:10.1101//m.031856.113

References This article cites 39 articles, 13 of which can be accessed free at: http://learnmem.cshlp.org/content/20/9/459.full.html\#ref-list-1

Creative This article is distributed exclusively by Cold Spring Harbor Laboratory Press for the Commons License first 12 months after the full-issue publication date (see http://learnmem.cshlp.org/site/misc/terms.xhtml). After 12 months, it is available under a Creative Commons License (Attribution-NonCommercial 3.0 Unported), as described at http://creativecommons.org/licenses/by-nc/3.0/.

Email Alerting Receive free email alerts when new articles cite this article - sign up in the box at the Service top right corner of the article or click here. 